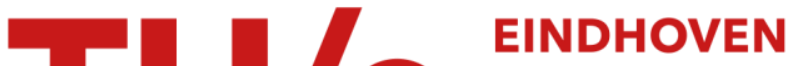 UNIVERSITY OF TECHNOLOGY
}

\section{Biases in incident reporting databases: An empirical study in the chemical process industry}

Citation for published version (APA):

Schaaf, van der, T. W., \& Kanse, L. (2004). Biases in incident reporting databases : An empirical study in the chemical process industry. In A. Lannoy, \& G. G. M. Cojazzi (Eds.), Decision Analysis : Methodology and Applications for Safety of Transportation and Process Industries : proceedings of the 23rd ESReDA seminar, Delft, November 18-19, 2002 (pp. 69-76). (EUR; Vol. 21004). Office for Official Publications of the EC.

Document status and date:

Published: 01/01/2004

\section{Document Version:}

Publisher's PDF, also known as Version of Record (includes final page, issue and volume numbers)

\section{Please check the document version of this publication:}

- A submitted manuscript is the version of the article upon submission and before peer-review. There can be important differences between the submitted version and the official published version of record. People interested in the research are advised to contact the author for the final version of the publication, or visit the $\mathrm{DOI}$ to the publisher's website.

- The final author version and the galley proof are versions of the publication after peer review.

- The final published version features the final layout of the paper including the volume, issue and page numbers.

Link to publication

\section{General rights}

Copyright and moral rights for the publications made accessible in the public portal are retained by the authors and/or other copyright owners and it is a condition of accessing publications that users recognise and abide by the legal requirements associated with these rights.

- Users may download and print one copy of any publication from the public portal for the purpose of private study or research.

- You may not further distribute the material or use it for any profit-making activity or commercial gain

- You may freely distribute the URL identifying the publication in the public portal.

If the publication is distributed under the terms of Article 25fa of the Dutch Copyright Act, indicated by the "Taverne" license above, please follow below link for the End User Agreement:

www.tue.nl/taverne

Take down policy

If you believe that this document breaches copyright please contact us at:

openaccess@tue.nl

providing details and we will investigate your claim. 


\title{
Biases in Incident Reporting Databases: An Empirical Study in the Chemical Process Industry
}

\author{
Tjerk van der Schaaf \& Lisette Kanse \\ Eindhoven University of Technology \\ Department of Technology Management \\ Safety Management Group \\ PO box 513, Pav. U-8, \\ $5600 \mathrm{MB}$ Eindhoven, The Netherlands
}

\begin{abstract}
The use of incident reporting schemes is becoming increasingly widespread in many domains such as industry, transportation, and health care; but the extent to which these schemes really capture a representative sample of actual events remains a topic of debate. While this has led several researchers to provide organisational design guidelines for the implementation of such schemes, much less is known about the individual reporter's perspective on contributing. Based on a literature survey and a diary study in which chemical plant operators reported events involving recovery from self-made errors, complete with reasons why they would or wouldn't normally report this, we identified six categories of reasons for not reporting. The distribution of the diary study events over these categories has highlighted a difference between the plant's operators and management, with regard to the perceived importance especially of successfully recovered events with no remaining consequences, or events considered to be nothing new. This difference should be addressed by communicating the learning potential of these types of events.
\end{abstract}

\section{Introduction}

Incident reporting schemes have a long history as part of organisational safety management programs, especially in sectors like civil aviation, the chemical process industry, and, more recently, in rail transport and in a few healthcare domains such as anaesthesiology, pharmacy, and transfusion medicine. In this contribution, we define incidents as all safety-related events including accidents (with negative outcomes such as damage and injury), near misses (where an accident could have happened had there been no timely and effective recovery), and dangerous situations.

But do these reporting schemes really capture a representative sample of actual events? One of the reasons why incident reporting databases might be biased lies in individual tendencies to over- or underreport certain types of events. The vulnerability of voluntary reporting schemes in terms of the quantity and quality of the incident reports has led to guidelines for designing and implementing such schemes. Reason (1997, p. 197) lists five important factors for "engineering a reporting culture": Indemnity against disciplinary proceedings; confidentiality or de- 
identification; separating the agency who collects and analyses the reports from the regulatory authority; rapid, useful, accessible and intelligible feedback to the reporting community; and finally, the ease of making the report. Similarly, Lucas (1991) identifies five organisational factors: the nature of the information collected (simply descriptive, or also causal); the use of information in the database (feedback, statistics, and error reduction strategies); analyst aids to collect and analyse the data; the nature of the organisation of the scheme (centralised or local, mandatory or voluntary). She also stresses the importance of the organisation's model of why humans make errors, as part of its overall safety culture.

These are just two examples of the well-documented organisational design perspective on reporting schemes. Much less is known about the individual reporter's perspective: when and why is one inclined to report a work-related incident to a formal scheme, and if so, what aspects exactly is one then able and willing to contribute?

The starting point for the investigation described in this paper was the observation that during a re-analysis of part ( $\mathrm{n}=50$ reports) of a large database of voluntarily reported incidents at a chemical process plant in the Netherlands, we hardly encountered any report of self-made errors Kanse, van der Schaaf \& Rutte (2002). This was surprising as this particular plant had been highly successful in establishing a reporting culture, where, apart from small damages, and dangerous situations, also large numbers of near misses (i.e. initial errors and their subsequent successful recoveries) were freely reported; on average two reports per day from the entire plant. Not only the circa 200 plant employees themselves, but also those temporarily stationed there by contractors equally contributed to the plant's near miss reporting system (NMRS). This NMRS had been operational for some seven years by the time we performed the re-analysis, and was regarded to be a "safe" system in terms of guaranteed freedom from being punished as a result of reporting an incident. Even more puzzling was the fact that these references to self-made errors were also absent in the particular subset of the database we were looking at: successfully recovered (initial) errors (human failures) and other failures, which were thus completely inconsequential. Our question therefore was: what are the reasons on the part of the plant operators for not reporting successful recoveries from self-made errors at this plant?

In this paper first we briefly summarise the (small amount of) literature on possible reasons for failing to report incidents in general, and evaluate its relevance for our particular research question. After generating a taxonomy of possible reasons for nonreporting, we describe a diary study where plant operators were specifically asked to report their recovery of self-made errors under strictly confidential conditions, outside of the normal NMRS used at the plant. In addition to their description of the recovery event, we asked them to indicate whether they would normally report this or not, complete with reasons why. The reasons given were categorised using the abovementioned taxonomy. The results are discussed in terms of identified reporting biases and possible countermeasures that the chemical plant could take to improve the validity of their existing reporting system. 


\section{Reasons for not reporting}

To identify the literature in which reasons for individuals to either report an incident or not are mentioned, we searched in both the Psychinfo and the Ergonomics Abstracts databases, so that we could draw from both the domains of work and organisational psychology and ergonomics, human reliability and safety. The key words we used were: reporting system and evaluation, reporting barriers, reporting tendencies, reporting behaviour, reporting biases, incident report, near miss report, and in Psychinfo even just simply 'near miss'. We included truncated forms (i.e. report* for report, reporting, and reports) of the keywords and alternative spelling to maximize the scope of our search. We assessed potential relevance based on the abstracts and added other references to our review process from the reference lists in references selected earlier. Our conclusion was that even though a relatively large amount of literature discusses organisational design guidelines for setting up an incident reporting scheme, only a few insights could be found in the reasons for individuals to decide whether to report an incident or not.

We have grouped the factors influencing incident reporting from the perspective of individual employees, that were mentioned in the literature, into four groups:

- Fear of disciplinary action (as a result of a "blame culture" where those who commit an error are punished) or of other people's reactions (embarrassment);

- Useless (perceived attitudes of management taking no notice, not likely to do anything about it);

- Risk acceptance (incidents are part of the job, cannot be prevented; or the "macho" perspective of "it won't happen to me");

- $\quad$ Practical reasons (too time-consuming; too difficult).

Adams \& Hartwell (1977) mention the blame culture (as does Webb et al., 1989) and the more practical reasons of time and effort as does Glendon (1991). Beale et al. (1994) conclude that the perceived attitudes of management greatly influence reporting levels see also Lucas (1991); and Clarke (1998), and also that certain levels of incidents are accepted as the norm. Similarly, Powell et al. (1971) finds that incidents may be seen as "part of the job" and cannot be prevented. This last point is supported by Cox \& Cox (1991), who also put forward a belief in personal immunity ("accidents won't happen to me"; see also the "macho" culture in construction found by Glendon, 1991). O'Leary (1995) discusses several factors that might influence flight crew's acceptance of their organisation's safety culture, and thus their willingness to contribute to the organisation's reporting program: trust towards management diminished by industrial disputes; legal judgments ignoring performance reducing circumstances; pressure from society to allocate blame and punish someone; the military culture in aviation; and the fact that pilots, justified or not, feel responsible or even guilty for mishaps, which is a result from their internal locus of control combined with high scores on self reliance scales. Elwell (1995) found that human errors are underreported in reporting systems in aviation, and suggests as explanations that flight crew members may be too embarrassed to report their mistakes, or they expect to be punished cf. Adams \& Hartwell (1977); and Webb et al. (1989); and especially when an error has not been observed by others, they are less likely to report. 
Although they have not looked at actual reasons for not reporting specific events, Smith et al. (2001), report clear differences (and thus biases in the recording system) between recorded industrial injury events and self-reported events collected via interviews and specifically developed questionnaires.

Outside the scope of the literature databases mentioned above, we identified a number of publications in the health care domain, in which only since recent years an increasing amount of attention is given to the reporting of adverse events, i.e. events with an observable negative outcome. An example is the study performed by Lawton \& Parker (2002), who studied the likelihood of adverse events being reported by different health care professionals, and found that reporting is more common in places where protocols are in place and not adhered to, and more likely to occur when patients were harmed, while near misses on the other hand are likely to go unreported. Explanations suggested for the reluctance or unwillingness to report are the culture of medicine, the emphasis on blame, and the threat of litigation.

Probably the most comprehensive study so far, and to our knowledge the only one where individuals were specifically asked to indicate their reasons for not-reporting, was undertaken by Sharon Clarke (1998), involving train drivers. She asked them to indicate their likelihood to report each of a standard set of 12 realistic incidents (a mix of dangerous situations, equipment failures, and other person's errors). The drivers were also offered a predefined set of six possible reasons for not reporting in each case: one would tell a colleague directly instead of reporting it; particular type of incident is just part of the job; to avoid getting someone else in trouble; the conviction that nothing would get done about this type of incident; reporting involves too much paperwork; or the conviction that managers would take no notice.

In what way can the above results be useful in generating a relevant set of possible reasons not to report recoveries from self-made errors? Taking the four groups of reasons reported in the literature (fear; useless; risk acceptance; practical reasons) as a starting point, we discussed this with three sections of the chemical plant's employees: management, safety department staff, and operators. Their opinions on possible reasons for non-reporting converged as follows:

- The chemical plant operators, being part of a high reliability organisation (HRO) or at least something close to that for a description of HRO characteristics see Roberts \& Bea (2001), were seen to be highly unlikely to put forward some of the reasons mentioned earlier; namely the idea of accepting incidents as part of their job, unavoidable, and not happening to them;

- The concept of the plant's management systematically ignoring reported risks, making the whole idea of coming forward with such information useless, was also not considered realistic;

- However, to some extent most thought it could still be possible that operators would be afraid or ashamed to report their own initial errors and mistakes triggering the necessity for subsequent recovery actions;

- Also they could consider it of less importance to report incidents that would be indicative of risks that they considered "no news", as they would be widely known amongst colleagues, minimizing their learning potential; 
- It was further proposed that some types of incidents could possibly be regarded as not applicable for the aims of the reporting scheme;

- Another suggestion was that the fact that they themselves, through their successful recovery, "took care" of the situation, would make it superfluous to report;

- The fact that there were no real remaining consequences in the end could possibly turn it into something unimportant;

- Finally, the time consumption aspect ("always busy") could of course play a role, as could other practical reasons (i.e. not yet fully aware of the system).

Integrating all of the above considerations we propose the following six possible reasons for not reporting recoveries from self-made errors:

- Afraid/ashamed;

- No learning;

- Not applicable;

- Recovery;

- No remaining consequences;

- Other.

\section{The diary study}

\subsection{Method}

Following the methods of previous studies in human error which used personal diaries to get reports of everyday errors Reason \& Mycielska (1982); Reason \& Lucas (1984); and especially Sellen (1994) we asked all members of one of the five shifts from the chemical plant if they would cooperate in a diary study. For a period of 15 working days ( 5 afternoon shifts, 5 night shifts, and 5 morning shifts) a total of 21 out of 24 operators filled out a small form for every case where they realised that they had recovered from a self-made error. The form contained items such as: describe the self-made error(s); what were the potential consequences; who discovered the error(s), how and when; what recovery action(s) were then taken; any remaining actual consequences; and finally: "Would you have reported such an incident to the existing Near Miss Reporting System (choose from yes/no/maybe)?", and: "Why (especially where the answer is no)?". For this vital last question we did not offer any of the preselected possible reasons as options, as we wanted to leave the operators as free as possible to express themselves in this respect.

\subsection{Results}

In the period of the diary study the 21 operators completed forms relating to 33 recoveries from self-made errors. In only three cases they indicated that this incident would also have been reported to the existing NMRS, while for five of the remaining cases no reason(s) for not reporting were indicated. Thus 25 cases remained. 
The literally transcribed answers of the operators to the last question were then given to two independent coders; one of them being one of the authors, the other one another human factors expert (not the other author) with ample experience in human error analysis. First, each of the coders identified the separate reasons from the transcripts: one coder identified 32 reasons in the 25 cases, while the other found two additional reasons. They then reached consensus on 32 identifiable reasons. After this, the two coders independently were able to classify each of these 32 reasons into one of the six categories. They agreed on 28 of the 32 reasons and easily reached consensus on those reasons coded differently. A typical example of each of the statements and the resulting code are shown in Table I. The overall results are shown below in Figure 1.

Table I: Examples of coded transcripts.

\begin{tabular}{|l|l|}
\hline Code assigned & Example from transcript \\
\hline No learning & The unclear/ confusing situation is already known \\
\hline Not applicable & System is not meant for reporting this kind of event \\
\hline Recovery & Because I made and recovered the mistake myself \\
\hline No remaining consequence & Mistake had no consequence \\
\hline Other & Not reported at the time: too busy then \\
\hline
\end{tabular}

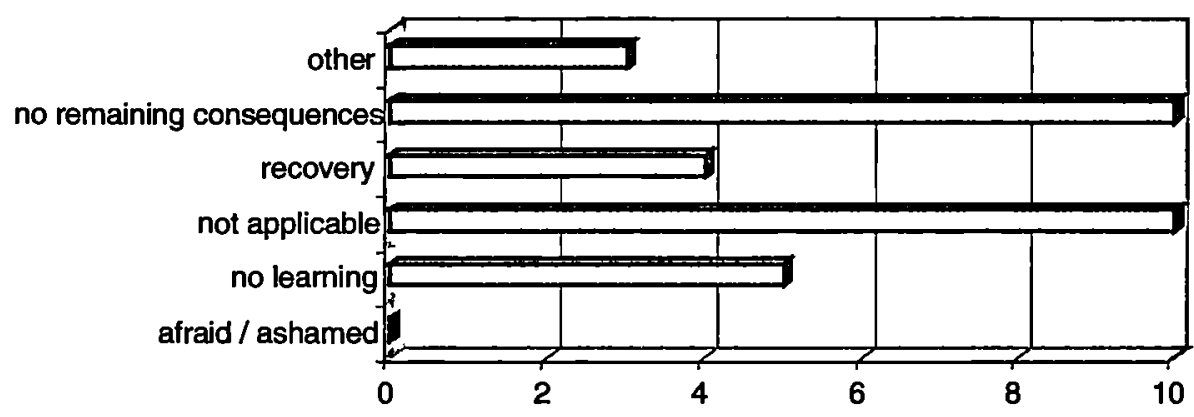

Figure 1. Distribution of 32 reasons given by 21 operators for not reporting 25 "diary incidents" to the existing near miss reporting system.

In addition to the results shown above, it is also worth mentioning that operators on average judged the potential consequences of the incidents in the diary study, had they not been recovered from, at the same level of seriousness as the incidents normally reported to the existing NMRS Kanse et al. (2002). Potential consequences that were distinguished in the studies for each reported event were: production/quality loss, delay, damage, injury/health effects, and environmental effects. A severity indication was also given for each type of consequence (no, minor, considerable, or major).

The remaining consequences after the recovery actions had been taken, however, another recovery process detail recorded for each event, differed from those indicated for the events studied in the re-analysed part of the existing NMRS database (where 50 events were analysed) again, see Kanse et al. (2002). After recovery from selfmade errors as reported in the diary study, in three events a minor delay remained, in one event minor production/quality loss, and one event involved minor repair costs. 
In contrast, in a much higher percentage of the 50 events from the NMRS (involving multiple, different types of failures per event), there were remaining consequences: in six events a minor delay remained, in one event minor health-related consequences, in four events minor environmental consequences, in 14 events the hazard continued to exist for a significant while before the final correction was implemented, and 20 events involved minor repair costs.

These findings suggest that a complete and successful recovery from self-made errors may be easier to achieve than from other types of failures or combinations thereof. The main difference lies in the repair costs involved and the time during which the hazard continues.

\section{Discussion and conclusions}

In terms of the trustworthiness of the results, the diary study was a success in complementing and checking the existing near miss database: respondents were very open and frank with the author who collected these data from them, which otherwise they would not have shared with the plant's management and safety staff. They also were quite clear in describing their reasons for not reporting. The fact that the second, totally independent, rater had no problem at all in using this taxonomy of reasons seems to indicate it's potential usefulness in the future.

Looking at the results in Figure 1, the plant's management and safety staff were somewhat surprised: some of them had suspected still some level of fear or shame to report one's own errors, and/or a lower level of perceived potential consequences as the major reasons for not reporting successful recoveries. Rather, the results show a genuine difference (between operators and management) in perceived importance, as measured by the options of no learning, not applicable, recovery, and no remaining consequences. It's up to the plant now to set up a program to clearly communicate their sincere interest in learning of the personal and system factors that make such successful recoveries possible, in stead of an attitude "all is well that ends well", which according to Kanse et al. (2002) is not compatible with how a high reliability organisation should function. On the other hand the complete lack of mentioning being afraid or ashamed to report one's own errors may be seen as a very positive indicator of the plant's safety culture.

The success of this limited (in time and resources) diary study would suggest to repeat this procedure sometime after the implementation of a program to convince operators of the importance to report (especially) successful recoveries: both to measure the impact on operators' perceptions, and to monitor from time to time for other, possibly new, reasons for not reporting. 


\section{References}

Adams, N.L., \& Hartwell, N.M. (1977) Accident reporting systems: a basic problem area in industrial society. Journal of Occupational Psychology, Vol. 50, 285298.

Beale, D., Leather, P., \& Cox, T. (1994) The role of the reporting of violent incidents in tackling workplace violence. In: Proceedings of the Fourth Conference on Safety and Well-Being, Loughborough, November, pp. 138-151.

Clarke, S. (1998). Safety culture on the UK railway network. Work and Stress, 12(1), 6-16.

Cox, S., \& Cox, T. (1991) The structure of employee attitudes to safety: a European example. Work and Stress, 5(2), 93-106.

Elwell, R.S. (1995). Self-report means under-report? In: N. McDonald, N. Johnston \& R. Fuller (Eds.): Applications of psychology to the aviation system, pp. 129-136. Aldershot: Avebury Aviation, Ashgate Publishing Ltd.

Glendon, A.I. (1991) Accident data analysis. Journal of Health and Safety, Vol. 7, 524.

Kanse, L., van der Schaaf, T.W., \& Rutte, C.G. (2002 - submitted). A failure has occurred. Now what?

Lawton, R., \& Parker, D. (2002) Barriers to incident reporting in a healthcare system. Quality and safety in health care, Vol. 11, 15-18.

Lucas, D.A.(1991) Organisational aspects of near miss reporting. In: T.W. Van der Schaaf, D.A. Lucas \& A.R. Hale (Eds.): Near miss reporting as a safety tool, pp.127-136. Oxford: Butterworth-Heinemann Ltd.

O'Leary, M.J. (1995) Too bad we have to have confidential reporting programmes!: Some observations on safety culture. In: N. McDonald, N. Johnston \& R. Fuller (Eds.): Applications of psychology to the aviation system, pp. 123-128. Aldershot: Avebury Aviation, Ashgate Publishing Ltd.

Powell, P.I., Hale, M., Martin, J., \& Simon, M. (1971) 2000 accidents: A shop floor study of their causes. Report no. 21. London: National Institute of Industrial Psychology.

Reason, J. (1997) Managing the risk of organisational accidents. Hampshire, England: Ashgate Publishing Limited.

Reason, J. \& Lucas, D. (1984) Using cognitive diaries to investigate naturally occurring memory blocks. In: J.E. Harris \& P.E. Morris (Eds): Everyday memory, actions and absent-mindedness, pp. 53-70. London: Academic Press.

Reason, J. \& Mycielska, K. (1982) Absent-minded? The psychology of mental lapses and everyday errors. Englewood Cliffs, NJ: Prentice Hall Inc.

Roberts, K.H. \& Bea, R.G. (2001) Must accidents happen? Lessons from highreliability organisations. Academy of Management Executive, Vol. 15(3), 70-77.

Sellen, A.J. (1994) Detection of everyday errors. Applied Psychology: An International Review, Vol. 43(4), 475-498.

Smith, C.S., Silverman, G.S., Heckert, T.M., Brodke, M.H., Hayes, B.E., Silverman, M.K., \& Mattimore, L.K. (2001) A comprehensive method for the assesment of industrial injury events. Journal of prevention and intervention in the community, Vol. 22(1), 5-20.

Webb, G.R., Redmand, S., Wilkinson, C. and Sanson-Fisher, R.W. (1989) Filtering effects in reporting work injuries. Accident Analysis and Prevention, Vol. 21, 115-123. 